\title{
An unusual case of Pasteurella multocida septicaemia
}

\author{
C. PENKeTH \\ M.B., B.S. \\ Edgware General Hospital, Edgware, Middlesex
}

\section{Summary}

A patient with recurrent septicaemic episodes due to Pasteurella multocida complicated by vertebral osteomyelitis and pseudo-membranous colitis is described.

KEY WORDS: septicaemia, Pasteurella multocida, osteomyelitis, colitis.

\section{Introduction}

Pasteurella multocida is a Gram-negative bacterium which is part of the normal oral flora of domestic animals such as cats and dogs. $P$. multocida can be recovered from $50 \%$ of infected animal bites, but septicaemia is rare in a normal person. It usually occurs in patients immuno-compromised by hepatic cirrhosis (Nadler, Freedman and Berger, 1979). A case of recurrent septicaemic episodes in an otherwise normal elderly woman is reported.

\section{Case report}

A previously healthy 83-year-old woman presented in August 1981 complaining of pain in her right leg and difficulty in walking. Five days before her admission, she had been bitten by a neighbour's cat in the right leg. Her general practitioner had vaccinated her against tetanus and treated her with flucloxacillin. She was otherwise well and there were no symptoms to suggest septicaemia.

General physical examination was within normal limits, she was afebrile and there was no lymphadenopathy. A small ulcerated lesion was present at the back of the right calf where she had been bitten. Haematological investigations showed a leucocytosis $\left(14.99 \times 10^{9} /\right.$ litre), an erythrocyte sedimentation rate (ESR) of $25 \mathrm{~mm} / \mathrm{hr}$. Routine biochemistry, including liver function tests, chest $\mathrm{X}$-ray and mid-stream urine were normal. $P$. multocida was grown from 3 sets of blood cultures. The organism was reported as sensitive to amoxycillin, erythromycin and benzylpenicillin, and the patient was started on oral amoxycillin, $1 \mathrm{~g}$ three times a day.
A few days later she became unwell with rige s, sweating, fevers $\left(38-39^{\circ} \mathrm{C}\right)$, tachycardia and sevige diarrhoea. Three sets of blood cultures were negatiye, but stool cultures revealed Clostridium difficile tox. Amoxycillin therapy was stopped and the patient was treated with vancomycin $500 \mathrm{mg}$ four times a day 5 days.

옥

With this therapy the fever remitted, the diarrhoea stopped, and she was well for several days. Shpe became unwell again with rigors, sweating, fevers $\left(38-39^{\circ} \mathrm{C}\right)$ and a tachycardia. $P$. multocida was again grown from 3 sets of blood cultures. Other investiga tions, as before, were normal, and stool cultures $\vec{E}_{1}$ C. difficile toxin were negative.

In view of the previous pseudomembranous \&ititis with amoxycillin, therapy was changed to erythrongcin $500 \mathrm{mg}$ four times a day orally. Further examination at this time revealed a left labial abscess whigh was drained surgically; cultures from the wound wofe negative. Her persistent symptom of lower backache was initially attributed to osteo-arthritis.

A few days after finishing a 14-day course of erythromycin, she again developed rigors, swe⿳亠口冋. ing, fevers $\left(38-39^{\circ} \mathrm{C}\right)$ and a tachycardia. Investigations still showed a leucocytosis $\left(13.9 \times 10^{9} /\right.$ lite) and a raised ESR. Other investigations as beforre including several blood cultures were negative.

A potential source of infection was again sought. Ultrasound of the liver and gall bladder and liver scan were normal. Bone scan showed no definite abnormality and $\mathrm{X}$-rays of the spine were reported-as showing only degenerative changes of osteo-arthritzs.

At this time treatment was restarted with amoxycitlin therapy $1 \mathrm{~g}$, three times a day, intravenous Whilst on this therapy, she remained well for 14 days. A few days later, she became unwell with rigors, sweating, fevers $\left(38-39^{\circ} \mathrm{C}\right)$ and a tachycardia. $\%$. multocida was again grown from 3 sets of bloßd cultures.

Her antibiotic therapy was reviewed and benz penicillin therapy was advised with vancomyoin orally to provide prophylaxis against further pseud\&membranous colitis. Re-examination of the patioft 
revealed marked tenderness in the lumbar region. A repeat bone scan showed an area of increased uptake in the region of the second lumbar vertebra and spinal X-rays now showed complete destruction of the second lumbar vertebra. An orthopaedic opinion confirmed the diagnosis of spinal osteomyelitis due to $P$. multocida with paravertebral abscess that had discharged through the ischio-rectal fossa accounting for the labial abscess.

This patient remained on benzylpenicillin therapy for several months, has had no more septicaemic episodes and has regained her weight and well being.

\section{Discussion}

Septicaemia due to $P$. multocida is rare in a normal person; the cases that have been reported have occurred in patients immuno-compromised by hepatic cirrhosis (Nadler et al., 1979). All previously reported cases of osteomyelitis caused by $P$. multocida developed by direct extension from an infected animal bite (Tindal and Harrison, 1972; Holloway, Scott and Adams, 1969). Vertebral osteomyelitis and a para-vertebral abscess due to this organism in an otherwise normal patient has not been described before, although they have been found in a patient with cirrhosis (Byrne, Thrall and Wheat, 1979). Our case was further complicated by pseudo-membranous colitis which is a rare complication of amoxycillin therapy (Richardson et al., 1981).

\section{Acknowledgment}

I thank Dr J. G. Lewis, Consultant Physician, for permission to report this case.

\section{References}

Byrne, F.D., Thrall, T.M. \& Wheat, C.J. (1979) Haematogenous osteomyelitis; Pasteurella multocida as the causative agent. Archives of Internal Medicine, 1182.

Holloway, W.J., ScotT, E.G. \& Adams, J.B. (1969) Pasteurella multocida infections in man. American Journal of Clinical Pathology, 51, 705.

Nadler, J.P., Freedman, M.S. \& Berger, S.A. (1979) Pasteurella multocida septicaemia. New York State Journal of Medicine, 10, 1581.

Richardson, S.A., Brookfield, D.S.K., French, T.A. \& BRay, J. (1981) Pseudo-membranous colitis in a 5-week-old infant. British Medical Journal, 283, 1510.

TINDAL, J.P. \& HARRISON, C.M. (1972) Pasteurella multocida infections following animal injuries, especially cat bites. Archives of Dermatology, 105, 412.

(Accepted 18 May 1982) 